\title{
NOVEL HPLC STATIONARY REVERSE PHASE COMPOUND DERIVED TO VALIDATE IRBESARTAN AND ITS IMPURITIES
}

\author{
V. Sathiyanarayanan ${ }^{1}$, H. Venkatasubramanian ${ }^{1,2}$ and D. Easwaramoorthy ${ }^{1, *}$ \\ ${ }^{1}$ Department of Chemistry, B.S.A.Crescent Institute of Science and Technology, Vandalur, \\ Chennai-600048, Tamilnadu, India \\ ${ }^{2}$ Department of Chemistry, Madras Institute of Technology Campus, Anna University, \\ Chennai-600044, Tamilnadu, India. \\ *E-mail: easwar@crescent.education
}

\begin{abstract}
A novel reversed-phase column was prepared by bio-degradable versatile biopolymer chitosan with 2-Hydroxy napthaldehyde condensed Schiff base (CSb). The prepared stationary phase CSb was characterized by FT-IR and its surface morphology was determined by Scanning electron microscope (SEM). From the SEM outcomes, fluffy and highly porous nature of the CSb was identified. Due to the porous and the insoluble in mobile phase, HPLC column was fabricated using CSb for analytical applications. The stability of the column was tested and found to be stable in acidic and basic medium. Using CSb column, anti-hypertension drug Irbesartan and its potential impurities were confirmed as per ICH guidelines and the results were linear, precise, rugged and accurate. The results of CSb column and commercially available HPLC column outcomes are exhibited similar results but CSb is a long life lowcost stationary phase.
\end{abstract}

Keywords: Irbesartan, HPLC, Reversed-phase, Stationary Phase, Active Content.

○) RASĀYAN. All rights reserved

\section{INTRODUCTION}

In past decades, the use of natural biopolymers in research has grown enormously due to its advantages like low cost, biodegradable, catalytic activity, low toxic, antibacterial, antifungal and antiviral activity. ${ }^{1-6}$ The chitosan belongs to the class of natural biopolymers, which is occurred naturally in the exoskeleton of the crustaceans' crabs and lobsters as in the form of chitin. ${ }^{7}$ The chitosan is obtained by deacetylation of chitin in presence of alkali medium. The chitosan is highly insoluble in organic solvents and soluble in dilute acids. So it can be used as packing material in column. The stationary phase solubility plays a vital role in all types of chromatography, which includes reverse phase, normal phase and chiral. Therefore, this study focused on the synthesis of biopolymer Chitosan Schiff base (CSb) using 2-Hydroxy 1napthaldehyde and chitosan. The product is characterized by SEM, DRS-UV, and FTIR techniques. The $\mathrm{CSb}$ is used as a stationary phase for reverse-phase in high-performance liquid chromatography (HPLC). Similarly, the commercial drug Irbesartan acts as an angiotensin-II receptor subtype I (AT1) antagonist which is used for medication of hypertension. So far, many spectroscopic and HPLC methods have been reported for the validation of Irbsesartan. ${ }^{8-10}$ So, this work emphasizes the synthesis and characterization of novel reverse phase column using stationary phase CSb derived from chitosan and 2-Hydroxy napthaldehyde. The HPLC column was fabricated using CSb and utilized as reversed-phase column for the determination and validation of Irbesartan in pharmaceutical formulations.

\section{Material and Methods}

\section{EXPERIMENTAL}

Chitosan and 2-Hydroxy 1-napthaldehyde were purchased from Sigma Aldrich, India and used as such without any further purification. The standards for Irbesartan and impurities were obtained from Madras pharmaceuticals (Karapakam), Tamilnadu, India. The formulated anti-hypertensive Irovel tablet $-300 \mathrm{mg}$

Rasayan J. Chem., 12(4), 2141-2148(2019)

http://dx.doi.org/10.31788/RJC.2019.1245419

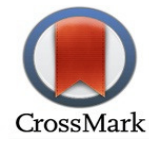


was purchased from commercial shops. Other reagents like HPLC solvents and water were bought from J.T.Baker (Phillipsburg, NJ, USA). Buffer salts for HPLC such as Ammonium Acetate, Orthophosphoric acid, Triethylamine were purchased from Merck (Darmstadt, Germany). The infrared spectrum for the prepared CSb was recorded using Perkin Elmer Spectrum Two. Diffuse reflectance spectra were recorded using Shimadzu UV-2450. The stationary phase CSb surface morphology was determined using a JEOL JSM- 6701F cold field emission scanning electron microscope (FESEM). The method validation was carried using UFLC system which was equipped with binary gradient pumps with autosampler and autoinjector (Model Prominence UFLC XR, PUMP LC-20AD, AUTO INJ SIL-20AC, OVEN CTO-20AC, PDA detector SPD-M20A, Dual UV detector SPD-20A, Make SHIMADZU JAPAN controlled with Empower software (Make: Waters, USA).

\section{General Procedures}

\section{Preparation of Stationary Phase Chitosan Schiff Base (CSb)}

$2(\approx 0.011$ moles) grams of 2-Hydroxy 1-napthaldehyde was treated with $25 \mathrm{ml}$ of methanol in $100 \mathrm{ml}$ round bottom flask and kept for stirring over a water bath at $50^{\circ} \mathrm{C}$. Further, 3 grams of Chitosan were added to the flask in three lots in 10 min time intervals and the reaction was kept for overnight stirring over the water bath at $60^{\circ} \mathrm{C}$. The yellow colour precipitate was obtained as per the Scheme-1 and the precipitate was washed with acetonitrile thrice to remove excess 2-Hydroxy 1-napthaldehyde. Then the solid was filtered and dried for $3 \mathrm{hrs}$ at $105^{\circ} \mathrm{C}$.

\section{Column Packing Method}

The prepared 2-Hydroxy 1-napthaldehyde derivative CSb was mixed with 500 grams of dry ice and ground in Robot Coupe. The mixture collected from the robot coupe after 1-hour grinding kept in refrigerator for 3 hours after the removal of dry ice. The CSb was dried in oven at $110^{\circ} \mathrm{C}$ for 3 hours. CSb column was prepared by wet slurry method which is displayed in Fig.-1. 6 grams of CSb was made slurry in $20 \mathrm{ml}$ methanol then poured into the pre-column and which was collected in the packing column. After the completion of packing, the column was connected to HPLC. The reservoir contains methanol as solvent. Approximately $10 \mathrm{ml}$ was allowed to pass through the packing column. About 5 liters of methanol was allowed to flow for three times inside the packing column. Then the column was used for analysis. Three columns were prepared using the same method for determining the repeatability of the CSb column.
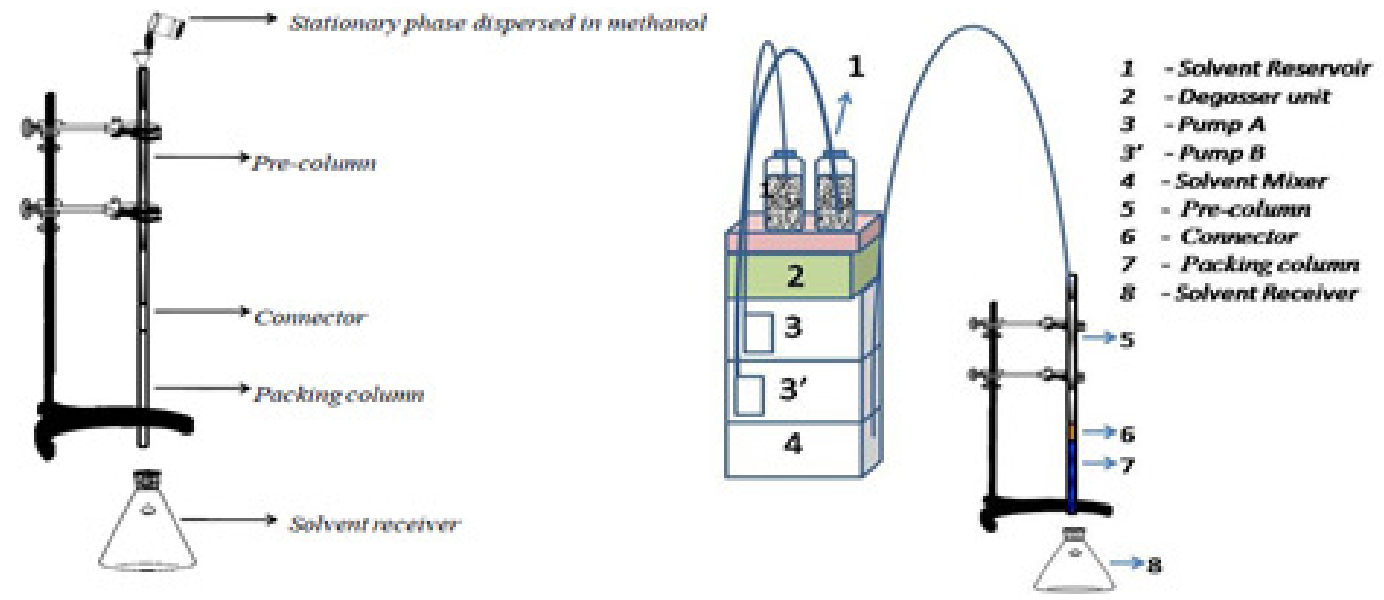

Fig.-1: CSb Loading and Packing in Analytical Column Model

\section{Validation Methodology}

The method was optimized by taking various trials and final conditions were investigated for the validation. Stationary phase symmetry CSb packed in 4.6 × $250 \mathrm{~mm}$ stainless steel column. The mobile phase consists of aqueous 0.02M ammonium acetate in Pump A and Acetonitrile in the Pump B and the 
50:50 ratio was set with the flow rate of $1.0 \mathrm{ml} / \mathrm{min}$. the validation conditions are fixed in HPLC such as column temperature $30^{\circ} \mathrm{C}$, cooler temperature $15^{\circ} \mathrm{C}$, injection volume $20 \mu \mathrm{l}$ and the detection wavelength is $220 \mathrm{~nm}$. The column was diluted with 1:2 ratios of water and Acetonitrile. The same ratio was used to rinse the standard Ultra-Fast Liquid Chromatography (UFLC). The method validation parameters include specificity, precision, linearity, accuracy, solution stability, robustness and filter validation.<smiles>CC(C)(C)CCN</smiles>

1<smiles>O=Cc1c(O)ccc2ccccc12</smiles>

2<smiles>CCCCC/N=C\c1c(O)ccc2ccccc12</smiles>

3

Chitosan

2-Hydroxynapthaldehyde

Schiff base of chitosan (CSb)

Scheme.1: Synthetic Route of CSb

\section{Preparation of Irbesartan and Impurity Stock Solution}

Irbesartan stock was prepared by dissolving $25 \mathrm{mg}$ in a $50 \mathrm{ml}$ volumetric flask and made up to the volume with diluent. Same way $2.5 \mathrm{mg}$ of process impurities (IMPU) such as IMPU-A, IMPU-B, IMPU-C IMPU-D and IMPU-E have weighed accurately and transferred into $50 \mathrm{~mL}$ volumetric flask made up to the volume with diluent.

\section{Preparation of Test Samples}

\section{API Standard and Formulation Samples Preparation}

Accurately $25 \mathrm{mg}$ of standard Irbesartan was weighed and diluted in a 100mL volumetric flask using the diluent. The quantity of drug content present in tablets was measured using finely crushed 20 tablets in mortar and pestle. From the crushed tablets, about $25 \mathrm{mg}$ of Irbesartan was weighed accurately and transferred into $100 \mathrm{ml}$ volumetric flask which was diluted by diluent. To make it clear solution, it was sonicated for 20 minutes then filtered and analyzed in UFLC.

\section{System Suitability}

The system suitability was investigated by transferring $4 \mathrm{~mL}$ of each impurity stock solution mixed together and diluted through the prepared 1:2 diluent. The diluted mixer was injected in HPLC and the outcomes noted up to 50min. the HPLC standard tablet stock and impurities outcome displayed in Fig.-2. This image represents the system suitability of the test samples for the validation.

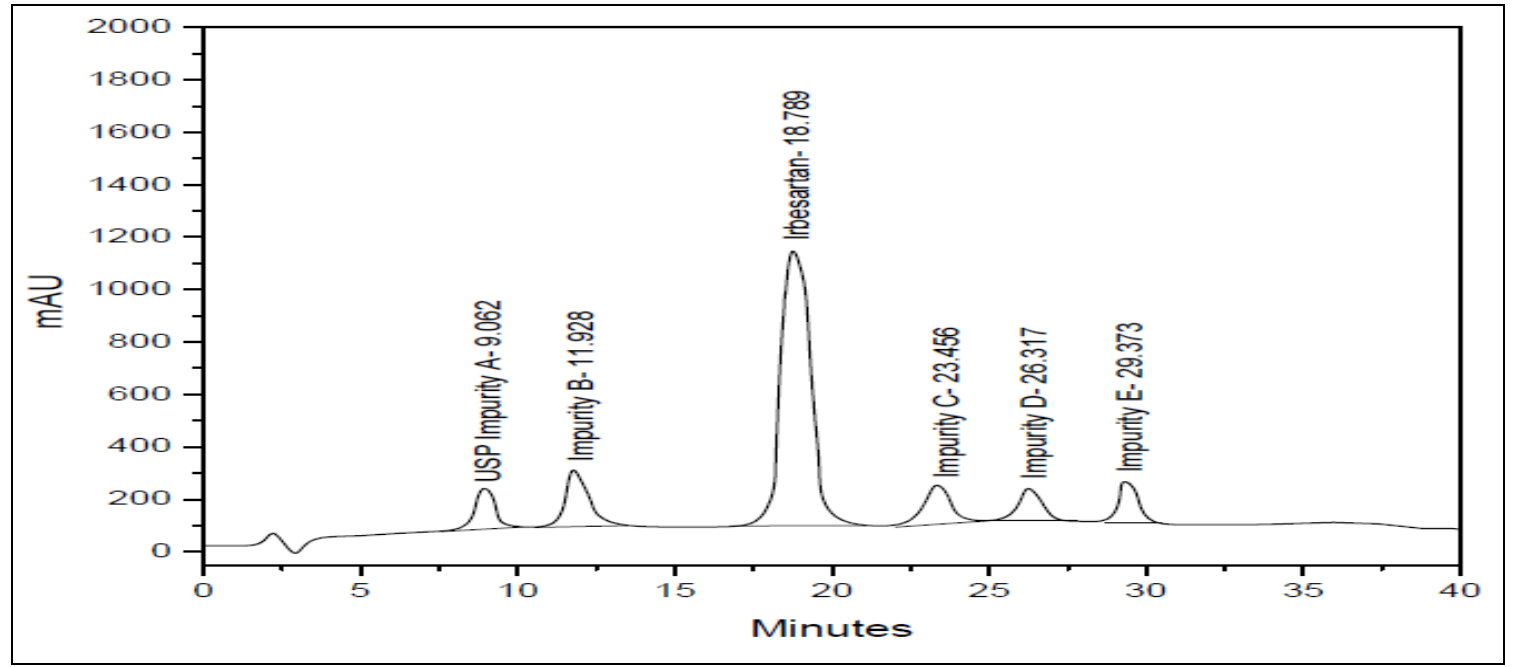

Fig.-2: Representative Chromatogram of Irbesartan and Its Impurities in CSb Stationary Analytical Column 


\section{RESULTS AND DISCUSSION}

This research synthesized the stationary phase by simple condensation reaction and the product isolated after the purification. The purified sample was characterized by FTIR and SEM for surface morphology. Based on the surface porosity, CSb was taken for the reverse phase HPLC column preparation.

\section{Surface Morphology of CSb by SEM}

The SEM analysis is employed for the surface morphology of the CSb for the adsorbent nature investigation. The SEM images presented in Fig.-3 at $30 \mu \mathrm{m}$ (a) and $10 \mu \mathrm{m}$ (b) capturing images.
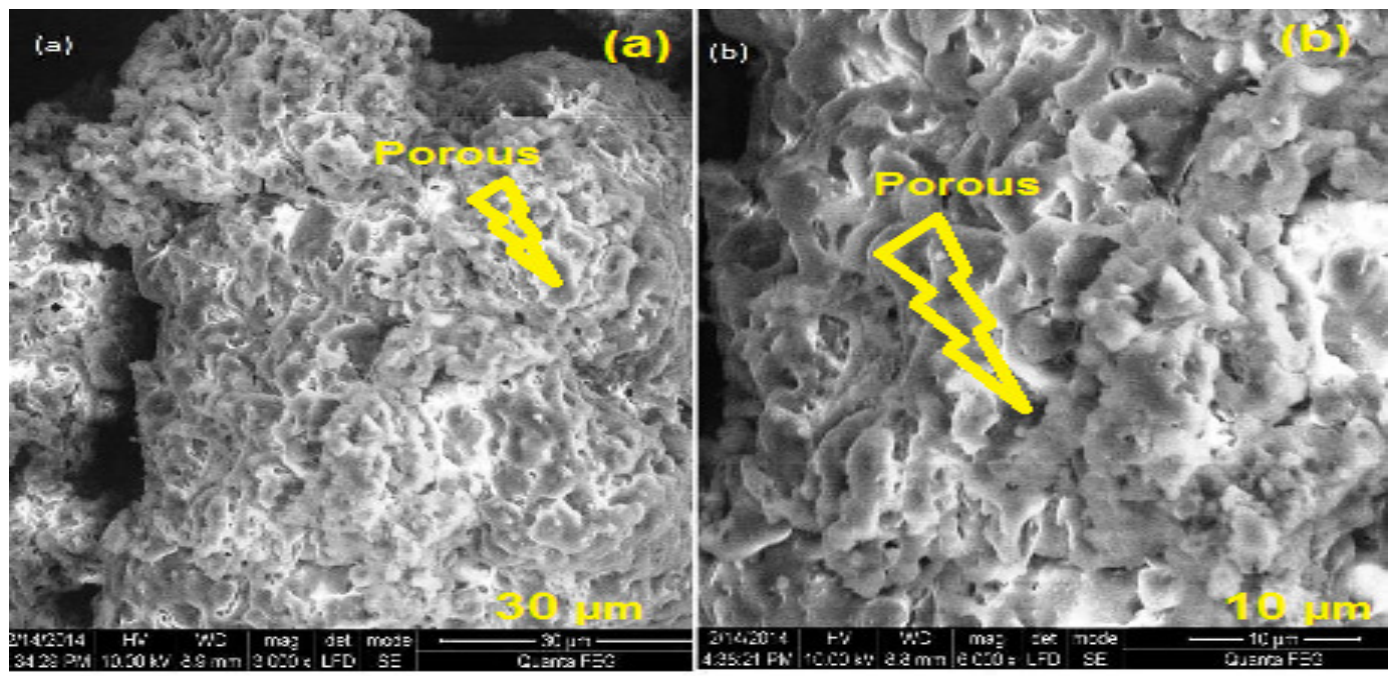

Fig.-3: Scanning Electron Microscope Image of CSb

These images revealed that the CSb is fluffy in nature and it has high porosity with increased in surface area. ${ }^{11}$ Due to the increased surface area, the material has a high capability for the retention of polar and non-polar analytes in stationary phase.

\section{FT-IR Characterization of Chitosan and CSb}

After the SEM characterization of the CSb, the starting material Chitosan and the Schiff base were characterized by FTIR for the functional group identification and have shown in Fig.-4. Stretching frequency for the CSb was observed at $1636 \mathrm{~cm}^{-1}$ (strong) which denotes the azomethine group of the product and it was absent in chitosan. ${ }^{12,13}$ In addition to that the hydroxyl group exhibited the broad peak at $3200 \mathrm{~cm}^{-1}$. These peaks confirmed the $\mathrm{CSb}$ and its functional group. Due to the well-known Schiff base formation reaction between the aldehyde and amine which was identified by FTIR characterization. Hence, this work carried the compound to fabricate the HPLC reverse phase column and used for the validation of the anti-hypertensive drug along with the impurities.

\section{Specificity}

The specificity of the test compounds was investigated using Irbesartan along with its impurities. The results were given in Table-1 and no interference was observed in the retention time window of the Irbesartan. The peak purity was obtained for the formulation sample and the API sample by PDA detector. From the outcome image, the peak purity is found to be less than the threshold value and confirms the absence of impurity co-elution in the Irbesartan. The optical purity image has shown in Fig.4. Irbesartan retention time (R.T) observed at 18.79 min without any interference.

\section{System Suitability}

System suitability was obtained by analysis $0.202 \mathrm{mg} / \mathrm{mL}$ of the test sample in HPLC using the standard reverse phase column. The reference column used HPLC data's are given in the below Table-2. The system suitability passes for the retention time RSD and theoretical plates resolution for all the impurities. 
RASĀYAN $J$. Chem.

Vol. 12 | No. 4 |2141 - 2148| October - December | 2019

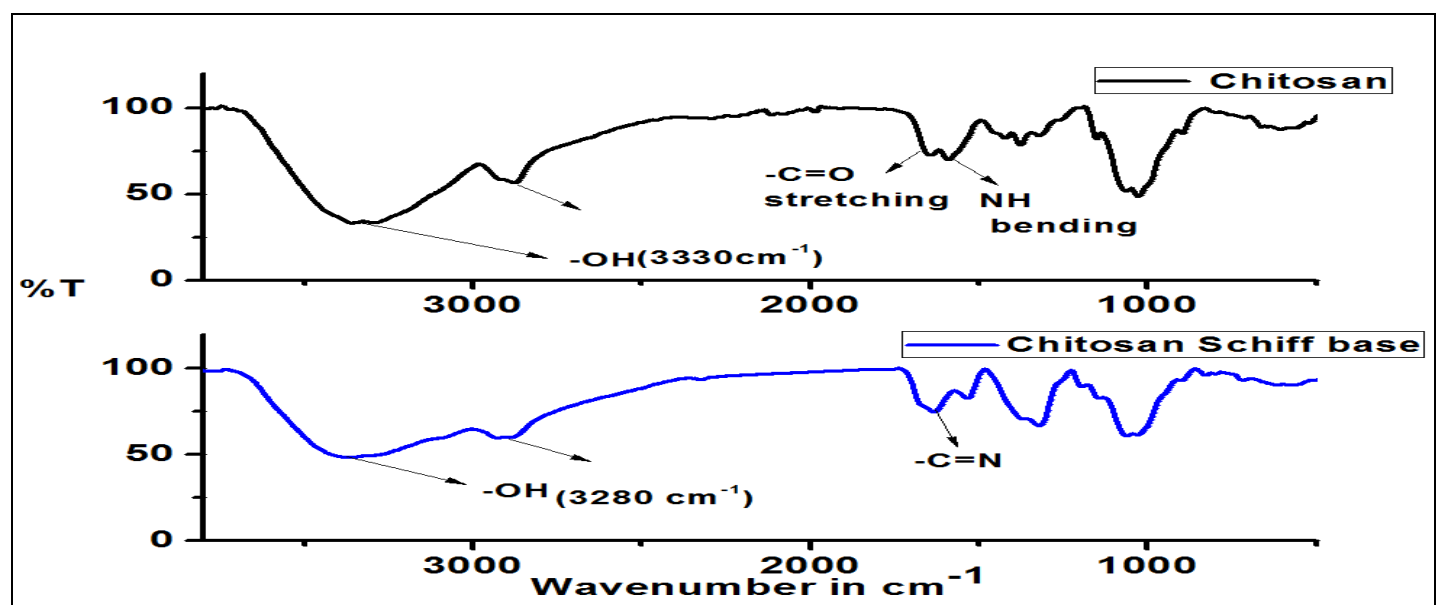

Fig.-4: FTIR Spectra of Chitosan and CSb

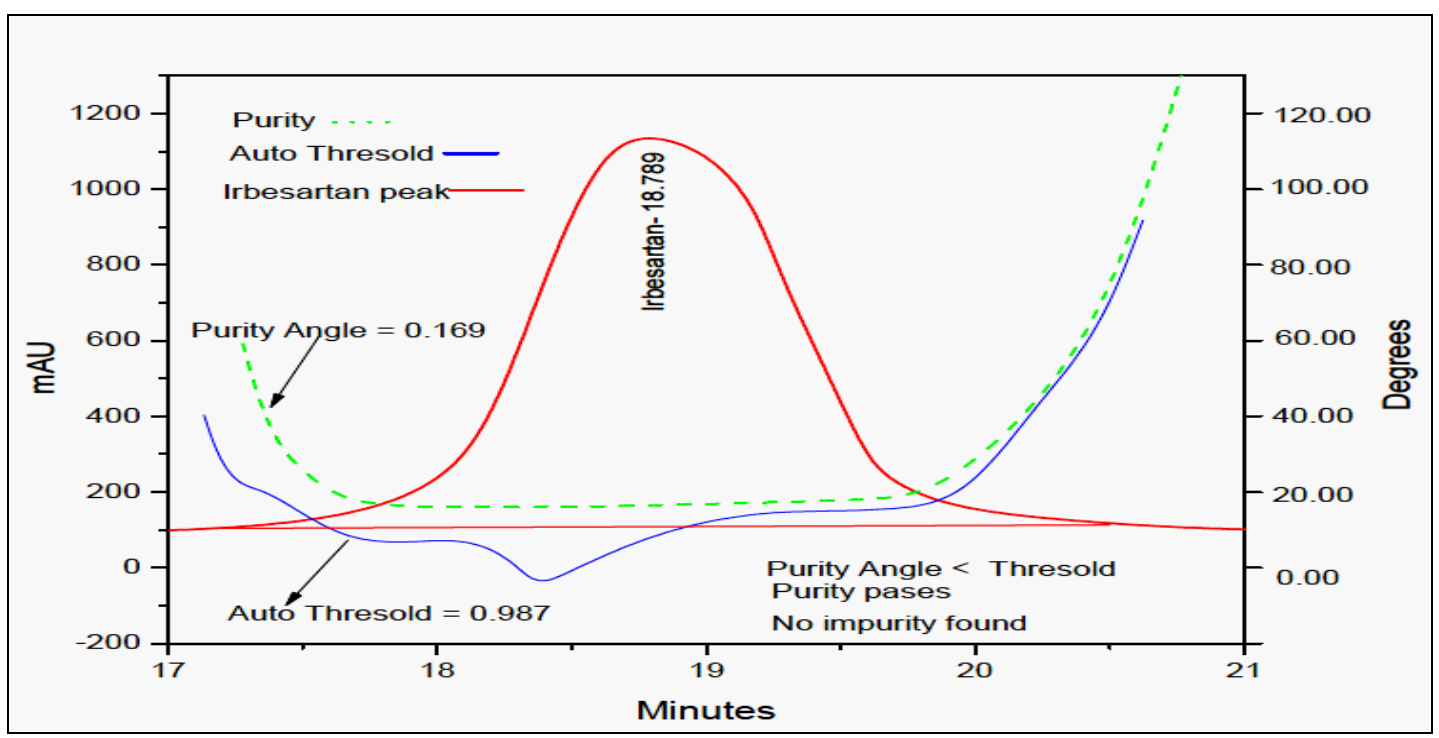

Fig.-4: Specificity by Optical Purity Using PDA Detector

Table-1: Specificity Results

\begin{tabular}{c|c|c|c}
\hline Compound Name & Retention time (minutes) & Relative retention Time & Interference \\
\hline Irbesartan & 18.79 & 1.00 & - \\
\hline USp Impurity A & 9.06 & 0.48 & - \\
\hline Impurity B & 11.93 & 0.63 & - \\
\hline Impurity C & 23.46 & 1.25 & - \\
\hline Impurity D & 26.32 & 1.40 & - \\
\hline Impurity E & 29.37 & 1.56 & - \\
\hline Irovel Sample & 18.76 & 1.00 & No interference \\
\hline Blank & - & - &
\end{tabular}

Table-2: System Suitability Results

\begin{tabular}{c|c|c}
\hline Compound Name & Resolution & Theoretical plates \\
\hline Irbesartan & - & 12453 \\
\hline USp Impurity A & 5.2 & 9456 \\
\hline Impurity B & 3.1 & 12459 \\
\hline Impurity C & 2.8 & 8025 \\
\hline Impurity D & 4.2 & 12825 \\
\hline Impurity E & 5.8 & 13845 \\
\hline Irovel Sample & - & 12500
\end{tabular}




\section{Linearity and Range}

Linearity and range of the detector response were obtained from the proportional concentration of the standard API and impurities solution. Linearity could be carried out by analyzing different levels ranging from 80 to $120 \%$ for API and L0Q to $150 \%$ levels for impurities. The results are presented in Table- 3 .

Table-3: Linearity Results

\begin{tabular}{c|c|c}
\hline Compound Name & $\begin{array}{c}\text { Correlation } \\
\text { Coefficient R }\end{array}$ & Theoretical plates \\
\hline Irbesartan & 0.9992 & 12453 \\
\hline USp Impurity A & 0.9998 & 9456 \\
\hline Impurity B & 0.9999 & 12459 \\
\hline Impurity C & 0.9997 & 8025 \\
\hline Impurity D & 0.9991 & 12825 \\
\hline Impurity E & 0.9994 & 13845 \\
\hline
\end{tabular}

\section{Precision and Accuracy Trials}

This work tested the precision and accuracy of the validation process for the powdered Irbesartan tablet. $75 \mathrm{mg}$ of the tablet powder solution was prepared in $100 \mathrm{~mL}$ standard flask using diluent and sonicated. The impurities were fortified in three levels such as LOQ level, 100\% level and 150\% level. Similarly, the standard also prepared in the order of $80 \%, 100 \%$ and $120 \%$ of impurity stock solutions and mixed well in the standard flask up to the mark. The samples were filtered through $0.22 \mu$ nylon filter paper and injected in the HPLC system through the standard column. Impurities were spiked in prepared different levels of solutions such as LOQ level, $100 \%$ and $150 \%$ within the acceptable Limits as per ICH guidelines. The triplicated recorded trials outcomes are tabulated in Table $-4,5$ and 6.

Table-4: Trial-1 Results

\begin{tabular}{|c|c|c|c|c|c|c|}
\hline Samp. ID & Impu-A & Impu-B & Impu-C & Impu-D & Impu-E & Irbesartan \\
\hline Level 1 Spl Prep1 & 0.010 & 0.011 & 0.011 & 0.010 & 0.010 & 79.0 \\
\hline Level 1 Spl Prep2 & 0.009 & 0.009 & 0.010 & 0.009 & 0.011 & 78.0 \\
\hline Level 1 Spl Prep3 & 0.009 & 0.010 & 0.010 & 0.009 & 0.011 & 78.0 \\
\hline Average & 0.009 & 0.010 & 0.010 & 0.009 & 0.011 & 78.3 \\
\hline Std. dev & 0.001 & 0.001 & 0.001 & 0.001 & 0.001 & 0.58 \\
\hline$\% \mathrm{CV}$ & 11.11 & 10.00 & 10.00 & 11.11 & 9.09 & 0.74 \\
\hline Mean Recovery & $90.0 \%$ & $100.0 \%$ & $100.0 \%$ & $90.0 \%$ & $110.0 \%$ & $97.9 \%$ \\
\hline \multicolumn{7}{|c|}{ Table-5: Trial-2 Results } \\
\hline Samp. ID & Impu-A & Impu-B & Impu-C & Impu-D & Impu-E & Irbesartan \\
\hline Level 2 Spl Prep1 & 0.090 & 0.090 & 0.100 & 0.110 & 0.090 & 98.3 \\
\hline Level 2 Spl Prep2 & 0.080 & 0.080 & 0.090 & 0.090 & 0.080 & 98.1 \\
\hline Level 2 Spl Prep3 & 0.090 & 0.080 & 0.090 & 0.090 & 0.080 & 97.9 \\
\hline Average & 0.087 & 0.083 & 0.093 & 0.097 & 0.083 & 98.1 \\
\hline Std.dev & 0.006 & 0.006 & 0.006 & 0.012 & 0.006 & 0.20 \\
\hline$\% \mathrm{CV}$ & 6.9 & 7.2 & 6.45 & 12.37 & 7.23 & 0.2 \\
\hline Mean Recovery & $87.0 \%$ & $83.0 \%$ & $93.0 \%$ & $97.0 \%$ & $83.0 \%$ & $98.1 \%$ \\
\hline \multicolumn{7}{|c|}{ Table-6: Trial-3 Results } \\
\hline Samp. ID & Impu-A & Impu-B & Impu-C & Impu-D & Impu-E & Irbesartan \\
\hline Level 2 Spl Prep1 & 0.14 & 0.15 & 0.15 & 0.14 & 0.09 & 118.0 \\
\hline Level 2 Spl Prep2 & 0.13 & 0.13 & 0.14 & 0.14 & 0.08 & 118.0 \\
\hline Level 2 Spl Prep3 & 0.14 & 0.13 & 0.14 & 0.13 & 0.08 & 119.8 \\
\hline Average & 0.137 & 0.137 & 0.143 & 0.137 & 0.083 & 119 \\
\hline Stdev & 0.006 & 0.012 & 0.006 & 0.006 & 0.006 & 1.04 \\
\hline$\% \mathrm{CV}$ & 4.38 & 8.8 & 4.20 & 4.38 & 7.23 & 0.88 \\
\hline Mean Recovery & $91.3 \%$ & $91.3 \%$ & $95.3 \%$ & $91.3 \%$ & $55.3 \%$ & $98.8 \%$ \\
\hline
\end{tabular}

\section{Stability Test of Standard and Sample Solutions}

After the precision and accuracy of the various levels, this work tested the stability of the standard API sample and the impurity mixed sample. Samples were prepared by fortifying with all known impurities at 
their specification levels and they were allowed to stand at room temperature. Solutions were analyzed at specified time intervals like initial, 24 days and 48 hours as per the validated method. The results were displayed in Table-7.

Table-7: Standard Solution Stability Results

\begin{tabular}{c|c|c}
\hline Time interval & $\begin{array}{c}\text { Standard Similarity } \\
\text { factor }\end{array}$ & Sample Similarity factor \\
\hline Initial & 0.99 & 0.99 \\
\hline 24 hours & 0.99 & 0.98 \\
\hline 48 hours & 0.98 & .98 \\
\hline
\end{tabular}

\section{Standard and Sample Stability with CSB Stationary Phase}

The Column Containing CSb was soaked with $0.1 \mathrm{M}$ Hydrochloric acid bypassing the $0.1 \mathrm{M}$ hydrochloric acid for 2 hours and then the column was rinsed with milli-Q-Water. The Irbesartan sample was assayed for six times and the results were compared with the precision results and the similarity factor was derived.

Table-8: Standard Solution Stability Results

\begin{tabular}{c|c|c|c|c|c|c|c}
\hline $\begin{array}{c}\mathrm{CSb} \\
\text { Condition }\end{array}$ & Parameter & Impu-A & Impu-B & Impu-C & Impu-D & Impu-E & Irbesartan \\
\hline \multirow{4}{*}{\begin{tabular}{c} 
Control \\
\cline { 2 - 8 }
\end{tabular}} & Retention time & 9.06 & 11.93 & 23.46 & 26.32 & 29.37 & 18.76 \\
\cline { 2 - 8 } & Content & 0.09 & 0.09 & 0.1 & 0.11 & 0.09 & 98.3 \\
\cline { 2 - 8 } $\begin{array}{c}\text { Treatement } \\
\text { with 0.1M } \\
\text { HCl }\end{array}$ & Content & 0.99 & 11.9 & 23.28 & 26.12 & 29.18 & 18.22 \\
\cline { 2 - 8 } & Similarity Factor RT & 0.99 & 1.00 & 0.99 & 0.99 & 0.99 & 0.97 \\
\cline { 2 - 8 } & $\begin{array}{c}\text { Similarity Factor } \\
\text { Content }\end{array}$ & 1.00 & 1.00 & 0.90 & 1.00 & 1.00 & 1.00 \\
\hline \multirow{4}{*}{\begin{tabular}{c} 
Treatement \\
with 0.1M \\
\cline { 2 - 8 }
\end{tabular}} & Retention time & 9.12 & 11.98 & 23.51 & 26.39 & 29.36 & 18.93 \\
\cline { 2 - 8 } & Content & 0.09 & 0.09 & 0.09 & 0.09 & 0.09 & 0.09 \\
\cline { 2 - 8 } & Similarity Factor RT & 1.01 & 1.01 & 1.01 & 1.01 & 1.01 & 1.04 \\
\hline
\end{tabular}

Through this, this work obtained satisfactory results in the similarity factor which suggests that column $\mathrm{CSb}$ is stable at acidic conditions. A similar experiment was conducted with $0.1 \mathrm{M}$ ammonium hydroxide for the test compound in prepared column and satisfactory results were obtained. This outcome confirmed the column and compound stability and can be used between $\mathrm{pH}=1$ to $\mathrm{pH}=14$. The similarity factor for Irbesartan assay for retention time and content in acidic and basic conditions was given in above Table- 8 .

\section{CSb Method Verification against USP Method}

The USP method was used as a reference for the verification of the newly fabricated CSb filled reverse phase column method. This work selected the reference HPLC column filled by Nucleosil C18 250mm, $4.0 \mathrm{~mm}, 5 \mu$ and make is Macherey-Nagel. The USP conditions such as wavelength-220 nm, buffer $\mathrm{pH}=3.2,5.5 \mathrm{~mL}$ of Phosphate buffer with about $950 \mathrm{~mL}$ of water, and the $\mathrm{pH}$ adjusted to 3.2 using triethylamine. The filtered and degassed mixture of $\mathrm{pH} 3.2$ phosphate buffer and acetonitrile $(67 ; 33)$ with $1.0 \mathrm{~mL} / \mathrm{min}$ was used as mobile phase and the run time fixed $40 \mathrm{~min}$ for the validation using Methanol (diluent). The representative system suitability HPLC recorded chromatogram for Irbesartan displayed in Fig.-5. The USP resultant chromatogram showed the equivalent results of newly fabricated column results. The related substances Standard deviation exist less than 1\% when compared with CSb stationary phase.

\section{CONCLUSION}

The newly prepared CSb compound showed good stability and result for the analysis of API Irbesartan. The stationary phase CSb is a biodegradable and cost-effective molecule. This method validated the drugusing newly fabricated column as per the ICH guidelines. This method can be adopted in bulk and 
formulation industries for Irbesartan and its impurities. Good results were obtained for this method and showed the validation parameters likewise linearity, specificity, method precision and assay accuracy. Moreover the column can be used wide range between acidic and basic mobile phase as the eluent system in HPLC. From this research, this work concluded that the results obtained through the column are rugged, accurate and precise. Hence this method can be used for the determination of Irbesartan and its impurities for formulation purposes. In addition to the outcomes, this work successfully prepared and fabricated long life low-cost HPLC column for the drug validation.

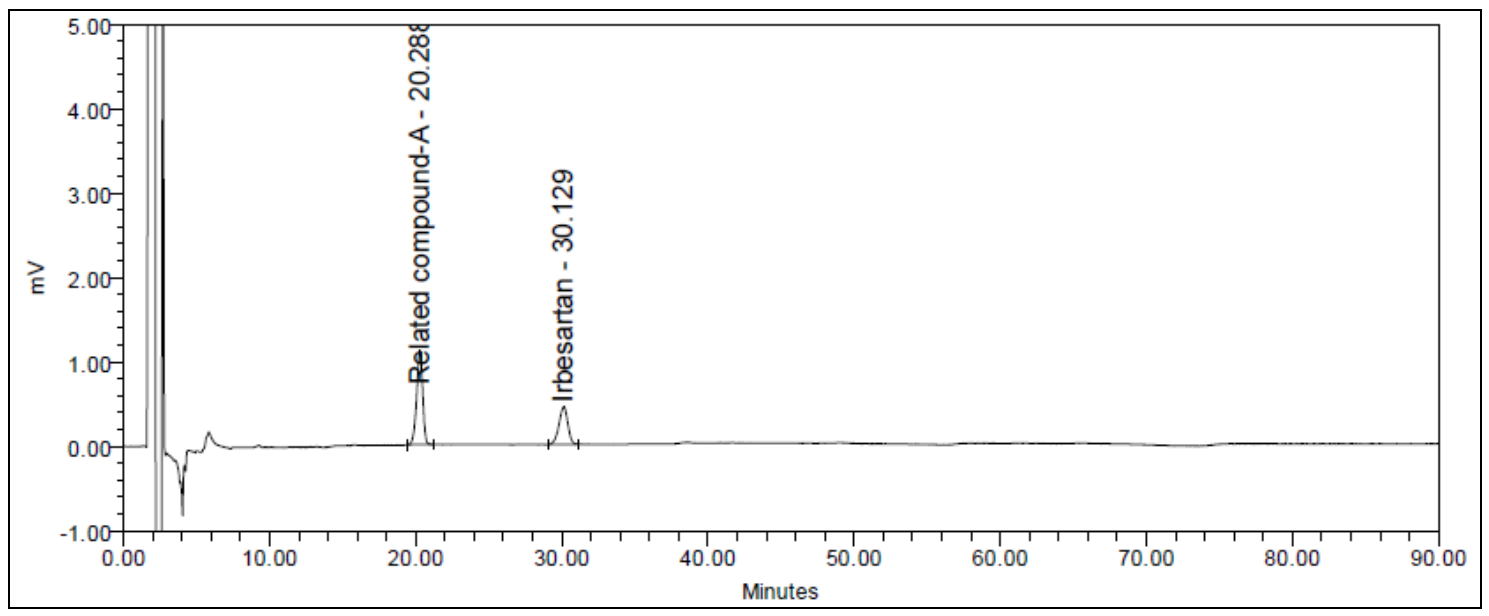

Fig.-5: System Suitability of HPLC for Irbesartan as Per USP

\section{ACKNOWLEDGMENT}

This research is not possible without the funding agency, Dr.R.Jayaprakash, Associate Professor, Department of Chemistry, SAS, VMRF, Paiyanoor, Vasan R\&D lab, and the author is always grateful to him for the science development.

\section{REFERENCES}

1. J. Xu, X. Zhao, X.Han and Y. Du, Pest Biochem. Physiol. 87(3), 220(2007), DOI:10.1016/j. pestbp.2006.07.013.

2. M.V.B. Reddy, J.Arul, P.Angers and L.Couture, J. Agric. Food Chem, 47(3), 1208(1999), DOI: $10.1021 / \mathrm{jf} 981225 \mathrm{k}$.

3. R.A.A. Muzzarelli, C. Muzzarelli, R. Tarsi, M. Miliani, F. Gabbanelli and M. Cartolari, Biomacromol, 2(1), 165(2001), DOI:10.1021/bm000091s.

4. V. Halabalova, L. Simek and P. Mokrejs, Ras. J. Chem, 4(4), 701(2011).

5. A.E. Hadrami, L.R. Adam, I.E. Hadrami and F. Daayf, Mar. Drugs, 8(4), 968(2010), DOI: 10.3390/md8040968.

6. H. Liu, J. Bao, Y. Du, X. Zhou and J.F. Kennedy, Carbohydr. Polym. 64(4), 553(2006), DOI:10.1016/j.carbpol.2005.11.007.

7. F.N. Hafdani and N. Sadeghinia, Int. J. Med. Health. Biomed. Bioeng. Pharma. Eng, 5(2), 46(2011).

8. R.Youssef and A. Hassan, Int. J. Curr. Res. Chem. Pharma. Sci., 1(4), 44(2014).

9. A.M. Alanaziali, A.S. Abdelhameed N.Y. Khalil, A.A. Khan and I.A. Darwish, Acta Pharm, 64, 187(2014), DOI: 10.2478 /acph-2014-0014.

10. P. Prabhu and M. Muralidhar, Int. J. Pharma. Sci. Drug. Res, 6(2), 145(2014).

11. M.A. Hassan, A.M. Omer, E. Abbas, W.M. A. Baset and T. M. Tamer, Scientific Reports, (8), 11416, 1(2018), DOI:10.1038/s41598-018-29650-w.

12. R. Antony, T. Arun and S.T.D. Manickam, Int. J. Biol. Macromol., 129, 615(2019), DOI:10.1016/j.ijbiomac.2019.02.047.

13. Z. Guo, R. Xing, S. Liu, H. Yu, P. Wang, C. Li, and P. Li, Bioorganic \& Medicinal Chemistry Letters, 15 (20), 4600(2005), DOI:10.1016/j.bmcl.2005.06.095.

[RJC-5419/2019] 